\title{
Review
}

\section{As if: Idealization and ideals}

\author{
Kwame Anthony Appiah \\ Cambridge, Harvard University Press, 2017, xvi+218 pp., \\ ISBN: 978-0674975002
}

Contemporary Political Theory (2021) 20, S29-S31. https://doi.org/10.1057/s41296019-00340-0; published online 29 July 2019

Some books, to paraphrase the old philosophical aphorism, are like hedgehogs: they unpack a single idea at great length and detail. Others are like foxes: they develop a wide variety of thoughts and claims, drawing on a range of contexts and disciplines. Kwame Anthony Appiah's As If: Idealization and Ideals, which is based on his 2013 Carus Lectures to the American Philosophical Association, certainly ranks among the latter. In characteristically clear prose and with great analytical rigor, Appiah discusses the phenomenon of idealizations: descriptions that we know to be false but that we treat for certain purposes (most importantly, to understand or control the world) as if they were true. For instance, we sometimes think of human beings as though they were perfectly rational utility maximizers, we treat smooth surfaces as though they were frictionless, or we assume that our political institutions are 'well-ordered' (all while knowing that they are not). By laying out the sheer variety of contexts, both in the humanities, science and indeed everyday life, in which these 'useful fictions' (p. 73) play an important role, Appiah seeks to encourage philosophers to reflect more systematically on the topic - to identify the false propositions that are being treated as true, to investigate why it might be useful to proceed as though these propositions were true despite their falsity, and to identify the purposes for which it is useful to proceed in this way (p. 170).

The topic of the book and its title pay tribute to the (largely forgotten) Germany philosopher Hans Vaihinger (1852-1933). In his main work, The Philosophy of 'As If' (1911), Vaihinger suggests that some of the most ground-breaking insights about the world, most importantly in the sciences, rely on what he called 'fictions': descriptions or theories that are literally false but that provide an easier and more useful way to think about certain subjects than the truth in all its complexity would. Appiah credits Vaihinger with the fundamental insight that 'in idealization we build a picture - a model - of something that proceeds as if something we know is false were true; and second, that we do so because the resulting model is useful for some purpose' (pp. 126, 127).

In the first two chapters of the book, Appiah is primarily concerned with the particular type of idealization that models human agents as (in some relevant sense) fully rational.

(c) 2019 Springer Nature Limited. 1470-8914 Contemporary Political Theory Vol. 20, S1, S29-S31 
Chapter 1 introduces Daniel Dennett's notion of an 'intentional stance' as an illustration. The thought is that when we take the 'intentional stance' toward a person, we treat them as if they were a rational agent with beliefs and desires. On this basis, we are more likely to be able to predict what they will do in order to further their goals. In Chapter 2, Appiah focuses on the idealized assumption, central to decision theory, that human beings are perfectly rational and that their degrees of belief satisfy the axioms of the probability calculus. On his view, the relevant idealization allows us to integrate the notions of degrees of belief and desire into a framework of analytic functionalism by characterizing them in terms of the functional roles they play in the mental lives of computationally perfect versions of ourselves, our 'cognitive angels' (p. 81). The idealized model of what belief would be like in an agent that conformed to that impossible ideal thus turns out to be useful in understanding something about the conceptual and logical properties of our actual beliefs.

My main focus in this review, however, will be on Chapter 3 (entitled 'Political Ideals - Lessons from John Rawls'), which is likely to be of most interest to readers of this journal. At this point, Appiah makes a sharp turn from thinking about idealizations in the context of philosophy of mind and action, to political theory. He is well aware that the shift to genuinely normative theory fundamentally transforms the nature of the problem, for our theory here does not aim at things how they are but how they ought to be (p. 144). Consequently, the relevant question is no longer whether an idealization helps us to understand or control the world, for 'how can we judge a theory's contribution to making the world better without already having an account of what it is for the world to be better?' (p. 130). Instead, the question is whether it yields norms and principles that are capable of guiding (i.e., can be realistically expected to be followed by) actual human agents. Which features of human social or psychological reality, in other words, do we have to take as given, and from which ones can we abstract?

It is fair to say that Appiah doubts that much contemporary political theory successfully draws this line. He thus joins a number of recent critics who worry about the prevalent tendency to 'seek to guide our actions in the actual imperfect world by the image of utopia' (p. 115). While Appiah problematizes the theories of justice developed by Robert Nozick and Ronald Dworkin, among others, his main target is John Rawls. Rawls famously distinguishes between ideal and non-ideal theorizing. When engaged in the former, we model ideal principles of justice while making counterfactual assumptions both about society (e.g., that its basic social institutions are 'well-ordered') and human agents (e.g., that they will accept and comply with the relevant principles). Subsequently we take into account the nonideal circumstances of the real world when it comes to specifying which version of an ideal is to be implemented, and how it is to be attained.

While Appiah clearly expresses unease about Rawls and much post-Rawlsian political theorizing, it is not that easy to pin down what precisely he is uneasy about. It seems that, in the course of the chapter, Appiah pursues at least three different lines of argument. First, there is a more general reflection on the right kinds of idealization in political theory. How ambitious can our normative principles be without losing touch with the 
world to which they are meant to apply? Here Appiah rejects theories that assume away too much (which may ultimately lead us to conclude that it is not even worth trying) and so makes the case for procedures that 'take into account what our best social science has to say about which norms it's realistic to expect people to follow' (pp. 123, 124).

A second line of argument is concerned with the relation between ideal and non-ideal theory. Appiah here does concede that 'there is a place ... for a range of kinds of political theory that are idealizing to different degrees' (p. 160). However, non-ideal principles should be worked out independently, rather than being derived (as in Rawls) from an antecedently worked out blueprint of a perfectly just society. For instance, an account of the ethics of migration that is guided by an ideal of a borderless world (which may very well be useful and important in some contexts) will blind or mislead us when it comes to non-ideal issues such as refugees (pp. 157-164). Appiah's third and arguably most radical claim adopts Amartya Sen's (moral-epistemological) argument that we are unlikely to know what a perfectly just society would even look like. The result is a form of incrementalism that does away with the need for ideal theory altogether ('the best is the enemy of the better', p. 164): all political theorists need are comparative judgments that one option is better than another (pp. 167-169).

While these questions are of course related, recent methodological debates in political theory have shown that they are worth differentiating. Of course, lack of argumentative detail is something to which Appiah unreservedly professes: his explicit aim is to 'stand back and take a broad view of a topic, knowing that real progress requires work with a narrower focus as well' (p.ix). But the question remains open whether (and how) political theorists can benefit at all from a research agenda that draws out abstract commonalities across a huge variety of fields of philosophical inquiry, or whether such a complexityreducing strategy does not actually end up obscuring more than it illuminates. After all, the specific challenges and predicaments of idealization in normative contexts are simply very different from the ones we face, say, in the philosophy of mind. That said, As If is full of interesting ideas, which are presented in a way that is both sophisticated and accessible to a wide audience. And it is surely a must-read for anyone interested in methodological questions in political theory.

Publisher's Note Springer Nature remains neutral with regard to jurisdictional claims in published maps and institutional affiliations.

Jakob Huber

Goethe University Frankfurt, 60323 Frankfurt, Germany

j.huber@em.uni-frankfurt.de 